\title{
Lecciones de ilusión: una introducción al estudio de la narrativa insólita de Pablo d'Ors
}

\author{
Lecciones de ilusión: An Introduction to the Study \\ of the Unusual Narrative of Pablo d'Ors
}

\author{
Raúl Fernández Sánchez-Alarcos \\ Universidad Pablo de Olavide de Sevilla \\ rfersan@upo.es \\ ORCID iD: https://orcid.org/0000-0003-4140-6800
}

\section{RESUMEN}

Se analiza Lecciones de ilusión destacando su singularidad dentro del panorama de la novela española actual, situándose la novela de d'Ors dentro de la tradición de la novela moderna centro-europea (Kafka, Mann, Kundera, etc.). Este trabajo tiene por objeto estudiar el tipo de representación de la realidad y de la existencia que se da en la novela. Descubriremos que la originalidad de d'Ors estriba en que, pese a situarse en la tradición de una novelística definida por su visión pesimista y desarraigada, utiliza, sin embargo, procedimientos narrativos modernistas para proponer finalmente una visión positiva y luminosa de la experiencia humana. Novela en la que, en definitiva, los planos de la realidad, la fantasía y la ficción se confunden para poner de relieve la condición ontológica y hermenéutica del ser humano: ser límite fronterizo del mundo.

Palabras Clave: novela modernista; metaficción; hermenéutica; ontología y arte.

\section{ABSTRACT}

Lecciones de ilusión is analyzed highlighting its singularity in the narrative contemporary Spanish novel. First of all, d'Ors's novel is situated within the tradition of the modern Central European novel (Kafka, Mann, Kundera, etc.). The objective of this work is to study the type of representation of reality and existence that is given in this novel. D'Ors uniqueness lies on his using Modernist narrative techniques which in the end depicts a shining self-assuring vision of human experience, despite him being part of a tradition in fiction marked by gloom-riddance and fatalism. A novel in which, in short, the planes of reality, fantasy and fiction are confused to highlight the ontological and hermeneutical condition of the human being: to be the frontier limit of the world.

Key words: Modernist novel; Metafiction; Hermeneutics; Ontology and art. 
El escritor Pablo d'Ors representa en la actualidad un caso sobresaliente de recepción literaria. Su breve ensayo Biografía del silencio se ha convertido en un best seller por el método de transmisión boca a boca. Su autor podría correr el riesgo de que le sucediera, salvando las distancias, lo que a Ángel Ganivet con su Idearium español, que su éxito lo fuera en menoscabo de la publicidad de sus novelas. Sin embargo, hay que reconocer que ha sido el eco alcanzado por este ensayo el que ha propiciado, en buena parte, la pervivencia de sus novelas en un mercado literario tan volátil como el presente en el que las novedades desaparecen enseguida de las librerías (Gullón 2004)1.

Este trabajo quiere contribuir modestamente a la recepción crítica de su obra narrativa, centrándose en el estudio de la novela Lecciones de ilusión, publicada en $2008^{2}$.

La obra literaria de d'Ors entronca con la tradición de la novela modernista, sobre todo europea, en su sentido más plenamente artístico; aquella que entiende la novela como arte que sirve, al igual que la poesía y la música, para la expresión creativa de la subjetividad, y no como producto cuyo contenido obedece exclusivamente a la demanda que ha hecho de este género literario el más popular desde el siglo XIX hasta nuestros días.

D'Ors ha declarado su vinculación con escritores como Kafka, Canetti, Mann o Kundera, entre otros. Sin embargo, se diferencia de estos en su deseo de ofrecer, como veremos, una respuesta positiva a la crisis axiológica que refleja, en general, la novela moderna. Respecto al lugar que ocupa la novela de d'Ors sería adecuado tener presente una doble perspectiva histórica. En primer lugar, desde una periodización de larga duración cabría situar la novela de d'Ors en el marco de la prosa y poéticas modernistas. Se reconocerá, de entrada, la dificultad de emplear una terminología que defina con rigor la novela que nos ocupa, sin incurrir en contradicciones o incoherencias conceptuales: «modernidad», «moderno», «modernismo» o «posmodernidad» son términos que se emplean en muchas ocasiones como sinónimos, lo que lleva no pocas veces a confusión ${ }^{3}$. La novela de d'Ors, que asume formas y contenidos

${ }^{1}$ En la actualidad, Galaxia Gutemberg está reeditando la obra completa de d'Ors.

${ }^{2}$ Introducción a un proyecto de estudio más amplio en vías de preparación (Pablo d'Ors y la literatura del límite). El presente texto se dio a conocer como ponencia en el II Congreso Internacional Figuraciones de lo Insólito en las Literaturas Española e Hispanoamericana (siglos XX-XXI). Universidad de León, 16-18 de octubre de 2017. Por ser incipiente la bibliografía sobre d'Ors, quiero dejar constancia aquí de las últimas aportaciones críticas aparecidas sobre sus novelas (Varo Varo 2018, 2019; Fernández Sánchez-Alarcos 2020).

3 Siguen siendo muy válidos los intentos de dilucidar críticamente este problema taxonómico por parte de Nil Santiáñez (2002, 87-135). Los juicios y análisis en torno a la novela posmoderna son muy variados, lo que hace que su definición sea, por el momento, bastante inestable y sujeta a controversia. Por ejemplo, utilizar el término de «posmoderni- 
de la novela modernista, se embarca en la misión de ensayar la expresión de una nueva concepción de «verdad literaria», para resolver el callejón sin salida al que ha llegado dicha novela: la práctica de una narrativa artística, de aspiraciones estéticas e intelectuales, trae aparejada la renuncia a que la novela refleje la totalidad del mundo. Si bien la extensa trama de Lecciones de ilusión refleja la visión fragmentaria propia de las artes que rompen con la tradición clásica, la novela aspira en su final a la consecución de un sentido pleno. Quizá por ello sea una novela de aprendizaje.

En segundo lugar, y desde el panorama presente de la novela española cabe adscribir la novela de d'Ors a unas corrientes narrativas cuyas estrategias tendentes a producir ambigüedad o hibridez genérica - entre la ficción, la autobiografía o la historia- están exigiendo de la crítica actual la necesidad de elaborar nuevas conceptualizaciones narratológicas. La narrativa dorsiana, en este sentido, se enmarca claramente dentro de lo que viene denominándose poética de la autoficción (Toro 2017). Si El olvido de sí, Contra la juventud y, especialmente, Entusiasmo plantean espacios transicionales y paradójicos entre la autoficción y autobiografía, en el caso de Lecciones de ilusión la autoficción revela, sobre todo, su dimensión metaficcional y autorreflexiva «... por la escenificación lúdica de la relación de un texto ficcional con su creador» (Toro 2017, 57). Asimismo, la instancia narrativa de Lecciones de ilusión se sustenta en principios perturbadores, sobre la base de recursos paradójicos y enigmáticos (Schlickers 2017): los niveles narrativos imbricados en la novela representan un juego de contraposiciones entre una ficción «real» y una ficción «ficticia» que traducen la tensión del estado de búsqueda interior de su protagonista en tránsito por estas dos dimensiones (la realidad y la ficción).

Por otra parte, un reciente estudio examina en la novela española actual una tendencia que se define por la reivindicación de la dimensión heroica del personaje, por la recuperación de la ejemplaridad como valor moral y por el uso de estrategias narrativas propias de la llamada novela de tesis. Son novelas que, como Soldados de Salamina y más recientemente El monarca de las sombras, de Javier Cercas, o Enterrad a los muertos de Martínez de Pisón, tienen por objeto reparar el sentido de ciertos acontecimientos históricos tergiversados por las versiones oficiales y que, además, se elaboran sobre «... le mode de l'énigme et adoptent la structure narrative de l'enquête, issue de roman policier» (Fauquet 2017,85 ). Hasta cierto punto, también podríamos situar la novela de d'Ors dentro de este paradigma crítico, pero para remarcar su singularidad respecto al mismo.

dad», que se entiende como periodo o época, para caracterizar una determinada novela como posmoderna (Pozuelo Yvancos 2004, 36-52; Navajas 2016, 31-55) puede ser equivoco, puesto que finalmente los rasgos definitorios propuestos coinciden con los que han servido para caracterizar la novela modernista. 
Lorenzo Bellini, el narrador y personaje principal de Lecciones de ilusión, pertenece a la estirpe de héroes novelescos de raíz romántica definidos por su subjetividad. Sin embargo, el aprendizaje de su protagonista tiene que ver precisamente con la superación de dicha subjetividad gracias al reconocimiento final de una identidad que se objetiva y que se hace pública y moral. Aprendizaje que no afecta solo a la evolución del personaje, sino que se extiende a la elaboración del propio relato: es novela, por tanto, de aprendizaje y al mismo tiempo metaficcional. Se podría entender, entonces, el proyecto novelístico de d'Ors como la superación del solipsismo narcisista ${ }^{4}$ a través de la práctica de una «literatura del alma» (Ibáñez 2004, 146). Esta acoge identidades en formación, cuya búsqueda vital concluye en una epifanía que repara la fractura producida entre el héroe y el mundo y recupera la centralidad del yo hasta entonces escindido. Se trata de evitar los efectos nocivos de la introspección complaciente que, a la postre, siempre «... se frustra debido a que la averiguación inquieta del 'quién soy', más que una indagación alcanzable es una expresión de obsesión narcisista» (Giddens 1997, 216). Es Lecciones de ilusión, entonces, una novela de aprendizaje, es decir, una novela formativa ética, según la entiende Eugenio Trías como «... el dificultoso ascenso que me permite acceder al lugar en el cual realizo mi medida singular: allí donde puedo cumplir mi vocación, deber, destino» $(1985,66)$. Lecciones de ilusión se escribe para dar cuenta de este «dificultoso ascenso» en el que el personaje descubrirá finalmente la llamada de una vocación. Cuando esta llamada se revela, el héroe reconoce que es precisamente en la relación con los otros $-\mathrm{y}$ no en el ensimismamiento- donde el yo se realiza como persona social intersubjetiva.

El fenómeno del narcisismo, como es sabido, se relaciona con los efectos de la modernidad: «Los orígenes institucionales de esta situación se hallan en la decadencia de la autoridad tradicional y en la formación de una cultura secular, capitalista y urbana» (Giddens 1997, 217). De ahí que la ciudad moderna se convierta en el escenario paradigmático de la novela a partir del siglo XIX, en ese escaparate fantasmagórico, tan bien descrito por W. Benjamin, sobre el que se proyectan los deseos no satisfechos del público (Buck-Morss 1989, 97-104). El consumo será la solución a esa insatisfacción pues remedia, aunque solo aparentemente, las necesidades de esta sociedad narcisista: belleza, juventud, éxito social... (Giddens 1997, 219). A esta disposición del ánimo José-Carlos Mainer la denomina «Narcisismo sentimental» (1994, 179-181) y, aunque la circunscribe al escritor español de finales del siglo $\mathrm{XX}$, sabemos que es rasgo propio de la modernidad literaria que inaugura el Romanticismo. La

${ }^{4}$ Para Hutcheon la noción de «narcisismo» no es necesariamente peyorativa: «...can be argued to be, not an aberration, but the 'original condition' of the novel as a genre» (1980, 8). Condición propia de aquellos relatos que son conscientes de su propia elaboración narrativa. En este sentido, convendría a Lecciones de ilusión la calificación de narcisismo diegético. 
crítica ha designado con diversos calificativos el fenómeno de la metaliteratura o metaficción: «novela narcisista metaficcional» (Hutcheon 1980), «novela lírica» (Gullón 1984), «novela ensimismada» (Sobejano 1988), o «discursiva y pensamental» (Sobejano 2004), por citar solo unos ejemplos notables. Lo cierto es que este tipo de novela autoconsciente comienza a manifestarse con la crisis de finales del siglo XIX -buen ejemplo de ello serían las novelas de Ángel Ganivet (Fernández Sánchez-Alarcos, 1995) - y su significación se comprende mejor dentro de una periodización de larga duración (Santiáñez 2002, 51-85). Frente al narcisismo propio de las sociedades modernas, el protagonista de Lecciones de ilusión adoptará, en su proceso de aprendizaje y frente al sistema convencional de valores burgueses, una actitud antidinámica: quietud y sosiego contra el ritmo vertiginoso de la vida moderna y desasimiento contra toda tentación de consumismo superfluo.

Como en todas las novelas de d'Ors, el texto de Lecciones de ilusión viene precedido de un dramatis personae: relación pormenorizada de personajes y escenografías que configuran el relato. Puede desconcertar esta información relacionada tradicionalmente con los géneros dramáticos. Sin embargo, se encuentra aquí una pista importante sobre el arte narrativo de d'Ors: en primer lugar, la tabla de personajes alude al carácter dinámico de la diégesis, implícito en el concepto de mímesis (Ricœur 1987, I: 83-94), y, en segundo lugar, nos indica que la ficción narrativa se concibe necesariamente como la puesta en escena de una representación de la existencia real. El dramatis personae es, por tanto, el anticipo de la construcción de la trama y de la disposición de los hechos en el tiempo y en el espacio, y no de la modalidad literaria que desde Aristóteles ha servido para distinguir el teatro del poema épico. De este modo, desde sus páginas preliminares la novela nos recuerda una evidencia de las artes miméticas: estas no son una copia de la realidad (como así lo sugiere una concepción burda de las artes realistas), sino una representación o figuración de la realidad.

No es de extrañar, por tanto, que d'Ors, para su propósito literario, opte por la novela, pues es el género por excelencia para investigar el alma humana en el tiempo: «... el tiempo se hace tiempo humano en la medida en que se articula en un modo narrativo, y la narración alcanza su plena significación cuando se convierte en una condición de la existencia temporal» (Ricœur 1987, I: 117). Así pues, la novela no explica el tiempo, pero sirve para comprenderlo y vincularlo al hombre.

Lecciones de ilusión se organiza formalmente del siguiente modo: consta de una lección inaugural («Creación y locura»), cinco lecciones centrales ( «Finis europae», «El corrector de estilo», «Las novelas eróticas», «El movimien- 
to y la quietud» $\mathrm{y}$ «El arte de la soledad») y una lección final («Literatura y fantasmas»). A lo largo de estas «lecciones» se nos cuenta cómo el narrador personaje, Lorenzo Bellini, llega al sanatorio psiquiátrico de Kremszell con el fin de redactar su tesis sobre las relaciones entre la locura y la creación. Una vez allí, Bellini entablará relación con toda una serie de personajes singulares y extravagantes: un cartero que despacha cartas imaginarias, el director de la institución, cuyo método clínico de «correlación» consiste en «... relacionar las enfermedades de sus pacientes con las de otros enfermos mentales de la historia» (99) ${ }^{5}$; el archivero del hospital, fiel cronista y notario de todo lo que dice el director; y los internos: un corrector de estilo, grafómano y bibliófilo obsesivo, empeñado en la redacción minuciosa de su biografía; un escritor de novelas eróticas que entabla entrevistas ilusorias; una especie de ermitaño que nunca abandona su habitación; un imitador de voces capaz de reproducir a la perfección cualquier voz, etc.

Comenzaremos el análisis de la novela señalando algunos nexos con la tradición literaria de la que parte d'Ors. En primer lugar, me voy a referir a la localización de sus novelas. Hasta la fecha, todos sus relatos, a excepción hecha de El olvido de sí (2013) y de Entusiasmo (2017), transcurren en países centroeuropeos. Se podría decir que estas novelas no hacen sino reflejar la experiencia vital de su autor, cuyos años de formación transcurrieron en ciudades como Viena, Roma y Praga. Solo Entusiasmo se enmarca, en buena parte, en un contexto español, pero por razones genéricas obvias: de todas sus novelas es la que más se aproxima a lo que entendemos por una autobiografía real y se centra en los años de juventud del personaje/autor en el Madrid de principios de los ochenta. Lo cierto es que, no sabemos si de forma premeditada o inconsciente, la novela de d'Ors parece sentir predilección por inscribirse dentro de una tradición literaria no localista. Ello hace destacar su atipicidad dentro del campo literario de la narrativa española contemporánea. Todas las referencias contextuales de sus novelas apuntan a esta dirección: no es solo el marco espacial, todos sus personajes son extranjeros, italianos, alemanes, así como las citas culturales. Lecciones de ilusión se escribe, pues, sin referentes españoles, salvo la mención, dentro de la ingente nómina de artistas y escritores citados en la novela, de solo cuatro nombres no distinguidos precisamente por su casticismo ${ }^{6}$. Por esta razón, y este es aspecto de mayor calado crítico, la novela de d'Ors se sitúa al margen de las tendencias que han polarizado la producción novelística hispana de los últimos años entre una novela social comprometida y una novela más «posmoderna» que se «... percibe como una experiencia barthesianamente lúdica o como una investigación estética que revierte sobre sí misma en una miríada de connotaciones y significados diseminados en el entramado cultural» (Navajas 2016, 26). En este

${ }_{5}^{5}$ En adelante, remitimos a la paginación de la edición, Lecciones de ilusión, Barcelona, Anagrama, 2008.

${ }^{6}$ Fernando Arrabal (176), La Cierva (230), Charlie Rivel (231) y Arnau de Vilanova (232). 
sentido, la vocación centroeuropea de d'Ors pone de relieve, por contraposición, un fenómeno recurrente de la novela española moderna. Desde Larra, las élites culturales españolas reconocerán -amargamente en muchos casos- la discontinuidad de la modernidad hispana frente al progreso arrollador de la Europa más industrializada (Torrecilla 2017, 347-360). La novela de d'Ors, al vincularse con referentes culturales y geográficos foráneos, con los que su autor se siente indudablemente cómodo y vinculado, se distancia abiertamente de esta constante de la literatura española contemporánea: la que ha hecho de la dialéctica centroperiferia una poética crítica y conflictiva en torno a la problemática modernización de España.

El espacio en el que acontece la acción de Lecciones de ilusión es el sanatorio de St. Bonifaz, sito en el valle de Kremszell, Alemania. Resuenan inevitablemente en el texto los ecos de La montaña mágica de Thomas Mann. El más notable es la oposición espacial dentro/fuera que afecta a la percepción del tiempo y a la construcción de la trama (Ricœur 1987, II: 201-231). Igual que en el sanatorio de Davos creado por Mann, en el de St. Bonifaz también rige un tiempo interior que no se mide por el exterior convencional. El protagonista reconoce al poco de su llegada esta peculiar circunstancia: «Como si fueran novelistas, han creado un mundo alternativo [...] porque el otro mundo que se llama real no les interesa» (189).

La visión fragmentaria y expresionista del mundo, propia de la novela experimental del siglo XX, también se recoge en Lecciones de ilusión. Elías Canetti explica así esta visión al referirse a su novela Auto de fe:

Un día se me ocurrió que el mundo no podía ya ser recreado como en las novelas de antes, es decir, desde la perspectiva de un escritor; el mundo estaba desintegrado, y sólo si se tenía el valor de mostrarlo en su desintegración, era posible ofrecer de él alguna imagen verosímil. Sin embargo, esto no significaba que fuera preciso escribir un libro caótico, en el que no hubiera nada inteligible, por el contrario, había que inventar, con una consecuencia extrema, individuos también extremos -como los que, en definitiva, integraban el mundo-, y yuxtaponer a esos individuos-límite, dentro de su disparidad. Concebí, pues, aquel proyecto de una «Comédie Humaine» de la locura... $(1981,417)$.

Lecciones de ilusión se elabora desde esta crisis moderna del paradigma clásico de unidad. Por eso sus «individuos-límite» se describen con un estilo narrativo marcadamente expresionista. El siguiente fragmento puede servir de botón de muestra:

Poseído por un frenesí incomprensible Ecker manejaba sus ficheros con una velocidad vertiginosa. Debido a su tamaño, los cajones ocupaban buena parte de la estancia cuando se abrían en su capacidad máxima. Por ello, y porque los cajones estaban a diversas alturas, si el asistente se olvidaba de cerrarlos o sólo los cerraba en parte, el aspecto del archivo podía recordar, visto desde cierta perspectiva, 
el de una composición abstracta: algo así como un laberinto por el que el archivero, acostumbrado al lugar, se movía con insólita destreza (91).

Pero hay que hacer una matización importante: el expresionismo en d'Ors no significa torsión negativa y crítica del hombre o de la sociedad. Responde, más bien, a una peculiar percepción de la realidad, según se desprende de estas palabras del narrador: «El estudiante captó enseguida que éste era precisamente el secreto del corrector de estilo y, acaso, el de todo escritor: otorgar una importancia desmesurada a todo lo banal, así como afanarse en comprender el significado de lo prosaico» (232 y 233). En la percepción de esa «desmesura» se encuentra la modalidad del expresionismo dorsiano a partir del sentido que en alemán tiene la palabra percepción: «... tomar (nehmen) algo como verdadero (wahr)» (Gadamer 1991, 78). Lo que perciben los sentidos no es algo superficial, sino que es algo que remite a la identidad misma del objeto observado. La mirada del escritor realista no posee este sentido de la percepción, abrumado o fascinado por la coerción uniformadora de la sociedad. Sin embargo, el estudiante aprenderá que lo excepcional puede surgir de improviso a la vuelta de cada esquina. Lecciones de ilusión viene a decirnos que cualquier ser humano por muy vulgar y corriente que sea puede contener algún viso de genialidad. La mirada atenta, es decir, ética y estética, es la que descubre la excepcionalidad en lo aparentemente más ordinario. De esa mirada surge el asombro por la forma, por el gesto expresivo, enérgico y dinámico. Un solo rasgo, trazado con énfasis, basta para caracterizar a los personajes, descritos, por ejemplo, por su andar en zigzag o en línea recta o por tener una nariz prominente o por equipararse con algún animal, como en el caso del personaje de Lucyna. Cualquier hábito cotidiano - por ejemplo, sacarse un pañuelo del bolsillo- puede llegar a ser singular por muy irrelevante que parezca:

Las primeras veces que había visto cómo Ecker sacaba su pañuelo y lo sacudía, antes de limpiarse el sudor o sonarse la nariz, la reacción de Lorenzo había sido de puro asombro. El asombro, pasado algún tiempo, se convirtió en admiración. Ahora, habituado ya, su reacción era simple y llanamente de alegría. Ya sólo por ese malabarismo, Ecker le parecía genial (166).

Expresionismo que no cae, pues, en la caricatura deshumanizada o esperpéntica al modo valleinclanesco. Aunque resulte paradójico, lo que pretende d'Ors al reparar de forma recurrente y obsesiva en una particularidad es precisamente destacar la humanidad del personaje. Así ocurre también con la función expresionista que cumplen los espacios en la novela.

Como se decía más arriba, los textos preliminares de las novelas de d'Ors contienen la lista de personajes y lugares del relato - «escenografías» las denomina el escritor-. Esta lista no es banal. Se descubre pronto que hay una estrecha interrelación entre el espacio y el personaje que tiene trascendencia metafísica y que no tiene nada que ver con el medio determinista de la novela 
realista o social. Las escenografías son espacios cultivados por los personajes que los habitan y donde hallan su sustento vital y espiritual ${ }^{7}$. Por eso están irremediablemente ligados a ellos como un monje lo está a su celda. Son lugares nunca traspasados, sino fecundados. Podría decirse, en este sentido, que el lugar encarna al personaje y viceversa. Lorenzo Bellini descubre pronto en St. Bonifaz este vínculo ontológico entre el hombre y su entorno: «Llegó casi a correr cuando se preguntó si no tendría cada ser humano su propio lugar en el mundo: Herr Direktor, su explanada, eso era claro; Lucyna, su pabellón de techos abovedados, también eso resultaba claro; Ecker su archivo... y ¿cuál sería el suyo?» (162). Para responder a esta pregunta el narrador escribe su relato. Por eso, al final de su relación, podrá decirnos que «... el espacio nos hace felices y el tiempo, en cambio, infelices» (618).

Pero Pablo d'Ors inicia su obra narrativa -se podría decir que espiritualmente- donde Mann o Canetti clausuran sus respectivas obras. También el narrador de Lecciones... reconoce que el novelista nace de un naufragio irremediable frente a «... la desilusión que ha experimentado ante el mundo» (190). Pero si en Canetti dicha desilusión lleva al escritor a captar solo fragmentariamente «alguna imagen verosímil» o en Mann a certificar irónicamente la muerte de la alta cultura europea, en d'Ors, por el contrario, el naufragio es germen de esperanza en el hombre a través del poder de la ficción: «Ningún novelista del mundo se daría a sus libros si no pensara que entre la portada y la contraportada de su manuscrito se encierra algún secreto sobre la condición humana» (190). En la cuarta lección, y por medio del personaje del Doctor Kien, bibliotecario de St. Bonifaz - ¿trasunto irónico del protagonista de Auto de fe del mismo apellido?- se resuelve la ecuación entre ilusión, novela y condición humana a partir del sentido del término «subrayar», en un texto que nos parece clave para la comprensión de la novela:

Subrayado: ilusión de posesión de las palabras bajo las que se traza. Letras: ilusión de las realidades a las que esas palabras apuntan. Realidades: ilusión de... -No terminó la frase-. Los subrayados cumplen respecto de las palabras que subrayan lo que éstas respecto a las realidades a que se refieren. Así pues [...], la finalidad de cualquier subrayado es invitar a leer las palabras y frases bajo las que se traza, ordenar lecturas futuras y reducirlas a lo esencial (436).

La palabra «subrayar» posee en la novela la eficacia y virtud metafóricas: «... los recuerdos [...] son los subrayados de la vida» (468); «Caminar y subrayar - por fin lo entendía Lorenzo- tenían para él un significado idéntico: caminar no era más que subrayar la tierra, dejar en ella la propia huella; y, en cuanto a subrayar, era así también como -en el texto- tendía al infinito» (482). «Subrayar», como en el caminante machadiano, es una condición vital de sen-

7 Son espacios entendidos como «límites/limes», según la filosofía del «límite» de Eugenio Trías, es decir, como «un territorio susceptible de ser habitado y cultivado» $(2014,183)$. 
tido en el tiempo. Subrayamos para saber esperar, para comprender el significado de nuestra existencia temporal, para marcar el fragmento de un texto o de un retazo de vida que deseamos sean finalmente reintegrados a una unidad íntegra de sentido frente al olvido y la desesperanza ${ }^{8}$.

\section{III}

La novela moderna es fruto de una crisis espistemológica. Algunos personajes de Lecciones de ilusión padecen el descreimiento de quienes han mordido la manzana envenenada de la modernidad. Al igual que el personaje de Lord Chandos de Hofmannsthal, temen que las palabras no puedan revelarnos la verdad, que el lenguaje no tenga equivalencia con la realidad: «... por primera vez en sus veinticuatro años Findeis se preguntó por el concepto de verdad, cuyos límites, claros y distintos hasta entonces, comenzaron a difuminarse para él. El joven perdió toda certeza» (62). Contra esta incertidumbre tan típica del hombre moderno Lecciones de ilusión va desgranando, a través de sus páginas, una especie de disciplina clericalis que contiene instrucciones lenitivas de uso: desasimiento ascético de todo lo material («... nada puede hacer tan feliz a un hombre como perderlo todo sin excepción» [487]); meditación por vía de la imitación («Guardar silencio, encerrarse en una habitación y atreverse a convivir con los propios fantasmas...» [488]); atención a todo lo que nos rodea para superar el sombrío narcisismo («Bastó el trino de un pájaro para que se derrumbase aquella melancolía. Basta un pajarito para que el hombre se olvide de sí mismo, aunque sólo sea un instante» [497]), y, finalmente, la comunión con la naturaleza y con Dios («-¡Dios! -se le escapó entonces a Lorenzo, sabedor ya de que hablar con los animales, como con el mismísimo Dios, era sólo una cuestión de tiempo, sólo una cuestión de soledad» [505]). Disciplina ascética que desemboca en una mística de lo esencial y que, frente al exceso de intelectualismo -siempre irónico y escéptico en el intelectual moderno-, descubre en lo banal el valor de la existencia y de la propia identidad:

A lo pequeño, al pensamiento sobre lo pequeño, sólo se llega después de haber pasado por lo grande. Por eso el pensamiento de lo pequeño es más importante,

${ }^{8}$ Sobre este carácter de la literatura que destaca el papel activo que tiene el lector frente al texto, la siguiente cita de Ortega y Gasset resulta muy esclarecedora: «Yo diría que el síntoma de un gran poeta es contarnos algo que nadie nos había antes contado, pero que no es nuevo para nosotros. Tal es la misteriosa paradoja que yace en el fondo de toda emoción literaria. Notamos que súbitamente se nos descubre y revela algo, y, a la par, lo revelado y descubierto nos parece lo más sabido y viejo del mundo. Con perfecta ingenuidad exclamamos: ¡Qué verdad es esto, sólo que yo no me había fijado! Diríase que llevamos dentro, inadvertida, toda futura poesía y que el poeta, al llegar, no hace más que subrayarnos, destacar a nuestros ojos lo que ya poseíamos» (1987 16 y 17). 
más sublime: un pensamiento al que sólo llegan unos pocos y, únicamente, al final. El término del pensamiento es lo banal: la puerta, la silla, el pajarito, la campana que suena, el mástil con la bandera... ¿Por qué es entonces tan invisible lo esencial? ¿Por qué sólo lo perciben quienes se encierran y tienen tiempo, quienes se entretienen con lo cotidiano? Bienaventurados los que aman lo banal -creo que podría decirse-, bienaventurados los que aman lo prosaico, porque sólo ellos comprenden y disfrutan de la poesía. La trascendencia de lo banal, la poesía de la prosa: ése es el secreto del verdadero silencio (507).

A través de su relato, Lorenzo Bellini va comprendiendo que la ficción hace posible la síntesis de lo heterogéneo, que es posible hacer inteligible la existencia del hombre a pesar de habitar en ese mundo desintegrado al que se refería Canetti. Pero ¿dónde surge esta posibilidad? En la ilusión, en lo insólito.

Ortega y Gasset, en uno de sus ensayos, definió al hombre como un «centauro ontológico» $(2000,47)$. Podríamos explicar el tipo de relación que se da entre ficción y realidad en Lecciones de ilusión a partir de esta feliz imagen. Si el idealismo decimonónico y el textualismo posmoderno niegan toda correspondencia entre la realidad y el lenguaje (Rorty 1996, 218), Lecciones de ilusión representa toda una declaración de fe en la literatura basada, como en toda fe bien entendida, en la posibilidad del desciframiento de un sentido y una verdad que, aunque no siempre inequívocas, nos remiten al mundo real. Si el idealismo admitía la existencia de una naturaleza última de la realidad en el ser espiritual del hombre, Lecciones de ilusión propone que esa realidad última se encuentra en la contemplación de la realidad misma. El protagonista de esta novela, Lorenzo Bellini, acomete un aprendizaje insólito de la realidad y de sí mismo desde esta condición fronteriza de «centauro ontológico»: la que lo ata al mundo, pero que, al mismo tiempo, desde el poder interior de la imaginación creadora lo trasciende (Trías 2014, 58-60). Se reconoce esta ambivalencia propiamente humana en la llamada experiencia hermenéutica. No hay realidad fuera de la comprensión que nos lleva a interpretar. El protagonista de Lecciones... aprenderá esta lección: la verdad no se descubre ahí fuera, sino que se encarna. Y cuando esto sucede nos referimos a la realidad de un modo insólito ${ }^{9}$. Por ello, esta novela, lejos de cualquier pensamiento débil, pone especial énfasis en mostrar el papel de mediación trascendental que entre la realidad y el lenguaje representa el relato de ficción como proceso de pre-figuración, figuración y re-figuración. Proceso hermenéutico que se constituye en tres fases. Primera: visión del mundo del escritor previa a la creación del texto; segunda: creación del texto, y tercera: apropiación del texto por parte del lector a través del sentido que le otorga (Ricœur 1987, I: 120-166).

La ilusión y lo insólito surgen, pues, de esta dialéctica entre ficción y realidad, que, en el fondo, remite a la relación entre creación y locura. Esta idea

${ }^{9}$ Charles Ives escribió que «(A)quel que ha escuchado una melodía musical teme que pueda hablar solo de manera extravagante» $(1982,77)$. 
se enuncia en la «Lección inaugural» de la novela. En ella se recrean unos episodios pertenecientes a las biografías respectivas de los escritores Robert Walser, August Strinberg y Friedrich Hölderlin. Inicia d'Ors de esta forma la especulación en torno a la naturaleza de la literatura y al oficio de escribir: ¿Qué lleva a un hombre a retirarse del mundo y a consagrarse a la escritura? ¿Es la enajenación la condición necesaria de la creación artística? ¿El hecho literario no es por sí mismo algo extraordinario por su naturaleza insólita? El narrador, en su labor rememorativa, reflexiona sobre estas cuestiones. Y el espacio privilegiado de esta reflexión es en la novela moderna -como en Niebla de Unamuno- el lugar/no lugar en el que se difuminan los límites convencionales entre la ficción y la realidad; lugar en el que el tiempo material desaparece para convertirse gozosamente en «tiempo propio» (Gadamer 1991, 104). Es decir, en tiempo insólito, que es el tiempo propio del creador, de la ficción, de la celebración, del juego y del enamorado. Tiempo propio en el que todo es posible porque en él el tiempo mensurable del reloj queda neutralizado. Por eso el narrador podrá extrañarse irónicamente de su presencia en la sala donde es juzgado Strindberg: «¿Es que no se habían percatado de mi presencia? ¿O es que me habían admitido, pese a ser varón, para ser testigo de este juicio ante la Historia? Todavía más: ¿sería yo invisible por pertenecer a otra época?» (37).

La novela, de este modo, integra en el relato mismo cuestiones propias de la teoría literaria, tales como la ficcionalidad o las «formas imaginarias de la actividad fantástica» (García Berrio 1989, 327). Cuestiones que, en última instancia, denuncian el establecimiento convencional de categorías entre literaturas más o menos miméticas, según su grado mayor o menor de verosimilitud. Presuponer que la novela fantástica sea más «ficticia» que la novela realista es un grave equívoco, puesto que, como pone de relieve Lecciones de ilusión, la novela es siempre ficción y representación.

Cuando se afirma en la 'Lección inaugural' que el sueño que persigue todo escritor es «... hacer algo de la nada, todo un mundo con palabras (24)», el narrador está confesando su vocación libresca. Pero en d'Ors la metaliteratura no se reduce a un mero exhibicionismo de juegos intertextuales; nace más bien de la necesidad de dialogar en compañía de obras y autores en la «... esperanza de una intelección esencial y plenaria.» (Laín Entralgo, 1964, 161). En el fondo, ficción y realidad deberían entenderse, así lo sugiere Lecciones de ilusión, como términos diferentes pero no opuestos. De ahí la necesidad tan unamuniana de recurrir a la expresión paradójica como medio de aludir a tan compleja relación. Por ejemplo, como cuando Lorenzo Bellini nos narra su entrevista con el ebanista Zimmer, el hospitalario admirador de Hölderlin: «Zimmer -le pregunto yo-, ¿se arrepiente de lo que ha hecho? / -En absoluto - me responde él, que ha acudido a mí en cuanto lo he invocado-. Fíjese que de no ser por esta hospitalidad, yo no habría pasado a la historia; iy ni siquiera estaría ahora hablando con usted!» (53). 
La lección inaugural se cierra con una confesión implícita de amor a la literatura. El narrador/protagonista/Lorenzo Bellini viaja acompañado de libros de los autores antes citados. Y, a modo de prolepsis narrativa, nos declara: «Claro que entonces, cuando comenzaba mi gran viaje a la locura, yo no sospechaba hasta qué punto aquellos textos iban a ser los más importantes para la futura conformación de mi vocación y personalidad» $(59)^{10}$. Es entonces cuando la novela nos anticipa su instancia narrativa: «Sólo ahora, concluida mi aventura, lo sé: tarde, como siempre; a la hora de la retrospectiva, puesto que sólo desde ahí -cuando ya ha pasado todo- es como se comprende la vida» (59). Es decir, el narrador de Lecciones de ilusión es un narrador memorialista que solo emplea la primera persona, como en el fragmento citado, para referirse al momento presente de la escritura - «la hora de la retrospectiva»- y usa la tercera persona para referirse a sí mismo como personaje evocado en el pasado. Al final de su relato insiste en este desdoblamiento narrativo: «A lo largo de los casi catorce meses de su estadía en el sanatorio, él ha cambiado y se da cuenta en este instante: en la retrospectiva, que es cuando se comprende casi todo» (627). Esta perspectiva narrativa tradicionalmente ha servido, como en el caso de La vida del Lazarillo de Tormes y su ilustre estirpe, que llega hasta la literatura de nuestros días, para contarnos la historia de una degradación moral. La de Lorenzo Bellini es, en cambio, la historia de una conversión moral.

Esta conversión solo es posible en el espacio de la ficción porque la búsqueda del personaje tiene lugar en el difuso ámbito de lo indeterminado, puesto en funcionamiento por el símbolo. Modo expresivo que no puede codificarse ni admite traducción directa, como la alegoría. Se trata, como en la mejor poesía, de un simbolismo generador de sentido que enfrenta al intérprete/lector a una experiencia hermenéutica insólita. Los personajes del sanatorio de St. Bonifaz llevan este problema de comprensión, como decíamos más arriba, al plano mismo del espacio físico: «Ante todos esos ocultamientos, tan reveladoramente repetidos, el estudiante tuvo que preguntarse si no sería St. Bonifaz un lugar donde, quien sabe por qué, todos deseaban ser invisibles» (141). La realidad ficticia de la literatura, como la vida misma, es inaprensible materialmente pues se muestra y se oculta al mismo tiempo: «El misterio de la fugacidad. La fugacidad como símbolo, perfecto y condensado, de la condición humana. Ir y venir, estar y no estar, aparecer y desaparecer, ¿no es esto, después de todo, lo que hacen los hombres en los diversos St. Bonifaz en que viven?» (155).

${ }^{10}$ D’Ors se muestra aquí más deudor del tópico clásico de la loa al libro, que del malestar que este produce al intelectual moderno. Ejemplos excelsos de este tópico pueden leerse en el Marcos de Obregón de Vicente Espinel (Descanso VIII) o en «El museo del discreto» de El Criticón de Gracián (segunda parte, crisi cuarta). En el polo opuesto, encontraríamos al hombre-libro, sabio deshumanizado de la modernidad que, por ejemplo, representan personajes como el Avito Carrascal de Amor y pedagogía, de Unamuno, o el profesor Peter Kien de Auto de fe, de Elías Canetti. 
Así pues, la fantasía en Lecciones de ilusión proviene de este indirecto «... modo de exposición que es el simbólico: se alude siempre de forma metonímica a una causa eficiente que trasciende y desborda nuestro conocimiento. Se da palabra y verbo a lo inconsciente» (Trías 1985, 104). Es evidente que a d'Ors no le interesa la literatura fantástica convencional. Si el director de St. Bonifaz tiene la facultad de desaparecer a su antojo, el narrador, frente a la constatación positiva de acto tan insólito, reacciona con preguntas retóricas que le llevan una reflexión final de alcance universal: «¿Cómo había podido esfumarse de un rincón donde no había puertas ni ventanas? ¿Tendría el don de la ubicuidad, el de la invisibilidad? ¿Sería el representante más perfecto del hombre contemporáneo, incapaz por naturaleza de la menor estabilidad?» (151).

Y tampoco en la novela de d'Ors tiene cabida el realismo ordinario porque la novela no es un calco de la realidad ni un medio para transmitir un mensaje extraliterario. El fin de la novela es la propia novela. Aquí d'Ors no hace sino seguir una concepción moderna del arte como vía de experiencia ontológica. La obra de arte «... no solo remite a algo, sino que en ella está propiamente aquello a lo que se remite. Con otras palabras: la obra de arte significa un crecimiento en el ser» (Gadamer 1991, 91). Experiencia, pues, que se enmarca en el simbolismo moderno como medio de redefinir la relación del hombre con el mundo a través de un saber no especulativo ni racional ni urbano. Saber solitario contrario al dictamen clásico y socrático vertido por Platón en el Fedro: «Me gusta aprender. Y el caso es que los campos y los árboles no quieren enseñarme nada; pero sí, en cambio, los hombres de la ciudad» (1997, 317). Por el contrario, y al igual que la voz poética del poema «Árboles hombres», de J. R. Jiménez, que conversa con los árboles, Lorenzo Bellini, en las soledades del valle de Kremszell, acabará conversando con la naturaleza y sus criaturas: «Le había bastado estar solo, un poco solo, y había conseguido hablar con un pájaro desconocido e invernal. ¡Y antes incluso que con Dios, el invento más perfecto de los solitarios!» (505).

De ahí que d'Ors entienda la mímesis aristotélica en clave exclusivamente metafórico-simbólica y quizá, por ello, los personajes de su novela hagan gala de una sólida conciencia filológica. Antes de iniciar su viaje, Lorenzo Bellini estudia el término «Kremszell», que da nombre al valle en el que se ubica en el sanatorio de St. Bonifaz y cuya confusa etimología hace presagiar al personaje un destino incierto: «La sensación que tuvo durante sus preparativos de lo cambiante e inaprensible, casi inefable, que era esa realidad, se verificaba ahora, a los pocos minutos de llegar» (74). La necesidad que tiene el narrador de asirse al significado de las palabras alude, en última instancia, al mundo como mapa lingüístico ${ }^{11}$. Para Lorenzo Bellini las palabras, ya muestren u oculten,

11 «... mundo humano, mundo de vida saturado de inteligencia lingüística, técnica y simbólica» (Trías 2014, 58 y 59). 
son como postes indicadores que nos sirven para variar y construir la realidad. En buena medida, la lección final que aprende Lorenzo Bellini es que en ese lugar-límite que constituye su morada vital «... inscribe el genio de la lengua su peculiar modo de reflexionar sobre aquello que acoge y recoge en sus propios juegos del lenguaje» (Trías 2014, 182).

Los moradores del hospital de St. Bonifaz también se resisten, como el nombre de Kremszell, a un significado simple y unívoco: «... todo en aquel sanatorio, desde su mismo nombre hasta el director que lo regentaba, era inaprensible» (154). Hacia el final de la primera 'Lección', en el parágrafo número veintiocho, titulado 'El gran teatro del mundo', se enuncia el tipo de existencia interior que representa la novela. El crepúsculo, lugar común privilegiado por la tradición literaria, acoge la siguiente revelación:

\begin{abstract}
Ahora, con pasos más cortos, Lorenzo camina por los senderos anaranjados de los jardines del sanatorio mientras el sol ha empezado a ponerse en el valle de Kremszell. Lleva todo el día caminando y no está cansado: el mundo externo ha sido devorado por una pasión interior. Él no lo sabe, pero es así como ha empezado a transitar por el camino de lo que los hombres llaman locura (156).
\end{abstract}

La locura insólita de Lorenzo Bellini tiene raigambre quijotesca, pues no conduce al personaje a mundos fantásticos ajenos a la realidad. Se interpretan, eso sí, las señales del mundo de modo extravagante, que es lo mismo que decir de modo figurativo por vía de la imaginación poética:

Quiso el destino que viera -o que al menos le pareciera ver- en cada una de aquellas sillas, plegadas o no, alienadas o, simplemente apiladas, lo que la noche anterior había visto en el pabellón acristalado: una colección de bustos, envueltos en la penumbra, en peanas a distintas alturas (229).

O como en el episodio de la puerta-Engelmann, donde la puerta -que recuerda el enigmático relato de G. H. Wells, La puerta en el muro-, adquiere una dimensión simbólica y misteriosa que, de nuevo, pone a prueba la conciencia racional del personaje, que no se contenta únicamente con una visión positiva o materialista de la realidad ${ }^{12}$ :

Claro que había quien afirmaba [...] que aquélla era una puerta falsa tras la que no había nada: sólo un muro, decían, o un vacío, o una idea alimentada -quién sabe con qué objeto- por la Dirección. Pero siempre hay quien dice que las puertas son falsas (y que las ideas, los dioses y hasta los amores son falsos). Saben que la puerta está ahí, pero prefieren no prestarle atención y viven como si no existiese. Como si no hubiera mundo y habitación, sino sólo mundo o sólo habitación. ¡Quién puede entender a los que no creen en las puertas! (425).

${ }^{12}$ La puerta es un símbolo recurrente en el escritor. Véase d'Ors 2013, 56-57. 
El sanatorio de St. Bonifaz, en su conjunto, representa en el capítulo «Finis Europae» el espacio de la vieja Europa, de la cultura europea, en concreto. Por St. Bonifaz pululan los fantasmas de los Maestros antiguos de Thomas Bernhard. Visión crepuscular con la que d'Ors establece un claro nexo con el espíritu crítico y pesimista del pensamiento que inaugura el siglo $\mathrm{XX}$ : «Esto es Europa, piensa el estudiante, que todavía contempla esta escena como si no fuera con él. Esto es lo que queda de Europa: una fiesta de viejos y enfermos al atardecer. Europa: champán y canapés» (177). ¿Quiere decirnos la novela que toda la cultura humanística ha quedado arrumbada en el siglo XX tras la barbarie bélica en la que se sumió Europa? Para el narrador, nos queda, sin embargo, un legado importante: «Europa ha muerto, ¡qué duda cabe!, pero sobreviven las locuras de sus genios» (177). Y nos queda también una opción para la que parece estar naturalmente predispuesto el «ser fronterizo del límite»: compartir la locura con esos genios y rescatar de sus obras aquello que pueda entrar en diálogo vivo con el presente. Pero este rescate no está exento de riesgos. Lo sabe el narrador cuando hacia el final de la novela, y aprendida quizá la lección más trascendental, puede decir: «Tenía sobrados motivos para sentirme dichoso: había conocido a unos cuantos seres extravagantes y me había dejado querer por ellos; había estado a punto de enloquecer, que no es sino el riesgo que se corre cuando se juega en serio con la identidad» (628). ¿Y jugar con la identidad no es buscar nuestro lugar en el mundo para habitarlo y cultivarlo? En este dejarse influir por obras ajenas, en esta necesidad de ser permeable a la cultura literaria, reside el riesgo en el que también repara George Steiner cuando escribe: «(L)eer bien significa arriesgarse mucho. Es dejar vulnerable nuestra identidad, nuestra posesión de nosotros mismos» $(2000,26)$. Con la identidad jugó y muy bien, como sabemos, el hidalgo Alonso Quijano.

En St. Bonifaz todos se entregan al juego de la ensoñación, pero de modo tan intenso y sincero que no es de extrañar que la fantasía termine por convertirse en realidad, como en el caso de alguno de los personajes imaginarios inventados por el cartero Kallmus que, repentina y sorprendentemente, cobran entidad real. La obsesión moderna por la metaliteratura quiere borrar los límites entre ficción y realidad, pero, como decíamos, en Lecciones de ilusión esta recurrencia no tiene que ver tanto con la problematización de la literatura, tema paradigmático de la novela modernista ${ }^{13}$, como con la progresiva convicción por parte del protagonista de que la verdadera ficción nos permite ver o conformar la realidad. Así, Lecciones de ilusión resolvería el dilema

13 Junto a los temas de «... la abolición de los vínculos, la comunidad problemática y la apoteosis de Narciso» (Pavel 2005, 337). 
axiológico entre idealización y realismo ${ }^{14}$ de este modo: frente a una imaginación que crea mundos quiméricos que nos alejan de la realidad o frente a una realidad determinista que niega la trascendencia, se opta por una imaginación creadora de ámbitos de inteligibilidad que, aunque insólitos o inverosímiles, nos aproximan paradójicamente a lo real verdadero. ¿Y esto cómo es posible? Si compartimos la tesis de Paul Ricœur (1987, I) de que la experiencia temporal e histórica del ser humano tiene una estructura narrativa, podríamos decir que el héroe de Lecciones de ilusión descubre que, más allá del intelectualismo formal, el ser humano tiene necesidad de amar y ser amado, de conocer y ser conocido; en suma, de narrar y ser narrado. Hacia el final de la novela, Lorenzo Bellini implora al cartero imaginario Kallmus que le dé más noticias de un corresponsal igualmente imaginario del que se ha enamorado. Dice entonces el narrador: «En este caso -quizá en todos- Walter Kallmus había adivinado la necesidad más imperiosa por la que clamaba aquel corazón» (560). ¿Y lo que clama ese corazón no es la necesidad de amar? Más adelante el narrador comprende la estrategia del cartero imaginario que es la que representa la vocación del verdadero creador: «Kallmus era un artista porque ponía en funcionamiento la fantasía e imaginación de aquellos con quienes convivía. Aliviaba su propia soledad aliviando la soledad ajena. Y ¿no es éste el sentido del arte, del verdadero arte? ¿No es ésta la meta final de la literatura?» (567).

Es así como Lorenzo Bellini, desde la melancolía extravagante que reina en St. Bonifaz, entra, como un nuevo don Quijote, en la ficción propuesta por el cartero y, como los verdaderos jugadores, lo arriesga todo apostando por el desvelamiento de un ilusorio amor epistolar. Contra el escepticismo irónico de la modernidad, el narrador sabe que el verdadero artista, ante el abismo del sinsentido, basa su creencia en la búsqueda incesante de otras formas de acceso a la realidad. Estas formas son la materia de la ilusión. No la ilusión ingenua o la ilusión materialista que solo percibe lo tangible, sino la ilusión que nace de la conversión: el hombre, a fin de cuentas, vive de la palabra, del amor y de un sentido que no se agota y que se proyecta siempre hacia un futuro indeterminado. Así, el narrador podrá decir:

El hombre que es feliz crea un espacio: una casa, un libro, un horizonte nuevo al que viajar y en donde hincar, aunque sea metafóricamente, una bandera. Pero ese mismo hombre feliz, con la bandera hincada y el libro escrito, ese hombre en casa se da cuenta de que por muy bien que ondee la bandera y por muy confortable que esté en su hogar, por justo y necesario que sea el libro que ha logrado escribir, ni la casa ni la bandera ni el libro dan la felicidad [...]. El hombre que es feliz crea espacios para la felicidad; pero ninguno de esos espa-

14 «... por qué, si el ideal pertenecía al mundo humano, éste estaba tan lejos, o bien, si el ideal no se encontraba en el mundo, por qué su valor normativo era tan evidente para todos» (Pavel 2005, 131). 
cios es la felicidad. ¿Cuánto tiempo tardaría Lorenzo en aprender esta lección, la lección del cartero? (588).

Y esto es tanto como decir que entramos en contacto con la verdad, con la felicidad, no a través del conocimiento sino de la comprensión. Cuando el cartero se marcha finalmente de St. Bonifaz, Lorenzo descubre que la felicidad no consiste en ser felices, sino en la posibilidad de mantener viva la ilusión:

Si todos fracasaban en sus sueños, si entre todas las historias que Kallmus inventaba no había ni una que fuera una historia feliz al ciento por ciento, ¿por qué no había en St. Bonifaz quien no lo amara? ¿Por qué lo miraban ahora como quien mira cómo se aleja una esperanza? (618).

A los seres que habitan St. Bonifaz les gusta jugar y jugar conlleva participar (jugar-con) y aceptar las reglas del juego. Con la ficción sucede lo mismo: esta solo funciona si el lector acepta jugar con la ficción en serio. Para que esto se dé son necesarios dos prerrequisitos: que el juego y la ficción merezcan la pena, y que el lector sea lo suficientemente atrevido y competente para arrostrar el riesgo de «recibir» y no «usar» la literatura (Lewis 1982, 69). Por eso, al final de esta novela de aprendizaje el Lorenzo narrador, que es el Lorenzo personaje que ya ha aprendido, puede confesarnos su idea de la literatura en la que podemos ver reflejada el arte poética de Pablo d'Ors. Lo que habíamos intuido en las lecciones previas, que la literatura tomada en serio es actividad insólita y fantástica, se certifica en esta declaración final:

La escritura es un trabajo manual; la literatura, un acto de fe: pero fe, sobre todo, en uno mismo; y fe, ciertamente, en los fantasmas. La clave de cualquier novela (de cualquier libro, diría) está en los fantasmas. La clave de cualquier novela está en otra novela que se quiso escribir y se traicionó. Porque nunca se termina por escribir aquello que se había pensado al principio. Porque nadie es nunca del todo quien ha querido y creído ser (638).

Lecciones de ilusión pertenece a la vieja tradición de la literatura sapiencial, pues su punto de vista es moral y, en el fondo, docente. Como se decía más arriba, los juegos metaliterarios y formales no se agotan retóricamente en sí mismos. Nos conducen, por contra, a la reflexión moral compartida en compañía de la tradición literaria. Por ello, finalmente, el narrador se ve en la obligación de cuestionar la materia semántica de su propio relato; la que pertenece a la memoria efectiva y la que pertenece a la memoria ficticia:

Yo había estado verdaderamente en aquel sanatorio alemán; pero ¿habría estado -como sostenía ante mí mismo- a punto de enloquecer? ¿Habrían existido Skarvada, por ejemplo, De Signore o Dorp tal y como los recordaba? [...]. Tal vez por eso me puse a escribir; para tener fe en lo que había vivido, para vivirlo y no perderlo definitivamente. Escribí mis Lecciones para saber lo que me había suce- 
dido en el valle de Kremszell más que para contarlo. Porque no se escribe para contar nada, como suele pensarse. Se escribe para saber quiénes somos (671).

Siguiendo al narrador de Lecciones diremos entonces que la novela también propone una lección al lector: se lee, o se debería leer, no para pasar el tiempo, sino para saber quiénes somos ${ }^{15}$. La conclusión de esta novela apunta, por tanto, a la búsqueda ontológica en relación con la experiencia artística. Nos precede toda una tradición artística consagrada a interpelarse sobre la identidad del ser. A esta inclinación del hombre a crear, visitar y revisitar obras de arte, J. A. Valente la denominó en un magnífico texto «querencia»: necesidad que tiene el ser humano, como ciertos animales, de volver al lugar en el que se ha criado y formado como persona ${ }^{16}$.

El reconocimiento de esas querencias, que no es otro que el reconocimiento de la tradición cultural, es requisito indispensable para el oficio del escritor: «...es preciso subordinarse a un estilo ajeno con vistas a la adquisición de uno propio. $\mathrm{O}$, lo que es lo mismo: un estilo propio no es más que la elaboración personal de uno ajeno. Toda la sabiduría del escritor, o casi toda, se cifra en escoger bien a su interlocutor» (675). Pero con todo, ese oficio de escritor, esos juegos metaliterarios, no son nada si no son en relación con. Llegamos así a la revelación que nos desvela la lección última y positiva de la novela: las «lecciones de ilusión» aprendidas por Lorenzo Bellini lo llevan a declarar su amor por el ser humano. Dentro de la tradición del humanismo más cervantino, el narrador nos confiesa: «Así que yo, el autor, tengo algo de libresco -lo reconozco- y de viajero -también lo reconozco-; sin embargo, lo que de verdad me define, lo que hace de mí un escritor (sólo ahora lo sé), es mi amor por la condición humana» (678).

Termino este trabajo enumerando los que considero los aspectos más relevantes de Lecciones de ilusión: en primer lugar, sin renunciar a los procedimientos narrativos más innovadores, esta obra quiere ser un contrapunto luminoso y positivo de la novela que aborda, como irresolubles, problemas del hombre moderno tales como la insuficiencia moral, la fragmentación del mundo o la dependencia del medio social; en segundo, d'Ors cuestiona el estatus teórico convencional de las llamadas literaturas fantásticas frente a las llamadas literaturas miméticas; y, en tercer y último lugar, dentro del panorama de la narrativa actual, Lecciones de ilusión representa una concepción de la novela

${ }^{15}$ Papel de mediación de la novela al que se refiere Unamuno en Cómo se hace una novela, cuando escribe que «(T)odo lector que leyendo una novela se preocupa de saber cómo acabarán los personajes de ella sin preocuparse de saber cómo acabará él no merece que se satisfaga su curiosidad» $(2005,598)$.

${ }^{16}$ «El hombre, como animal de naturaleza y como animal de cultura, ha privilegiado siempre ciertos lugares o ha sido privilegiado por ellos, en el sentido de que se le han presentado o se han constituido ante él como espacios de una particular revelación de su propio ser. Cabría llamar a esos lugares querencias...» (Valente 2006, 1355). 
fecunda y original al ilustrar una de las más profundas convicciones del pensamiento hermenéutico moderno: la identidad puede ser comprendida si es una identidad narrada. Es decir, la identidad, como la del narrador/personaje, Lorenzo Bellini, es la consecuencia de una vida contada, representada en la narración, y re-figurada por los demás a través de un diálogo permanente con la tradición cultural y literaria.

\section{BiBLIOGRAFÍA CITADA}

Buck-Morss, Susan.1989. Dialéctica de la mirada. Walter Benjamin y el proyecto de los Pasajes. Madrid: Visor.

Canetti, Elías. 1981. «El primer libro: Auto de fe». En Auto de fe, 411-420. Barcelona: Muchnik Editores.

Fauquet, Isabelle. 2017. Héros et nouveaux modèles. L'exemplarité dans le roman espagnol d'aujourd'hui. Rennes: Presses Universitaires de Rennes.

Fernández Sánchez-Alarcos, Raúl. 1995. La novela modernista de Ángel Ganivet. Granada: Diputación Provincial de Granada y Fundación Caja de Granada.

Fernández Sánchez-Alarcos, Raúl. 2020. «Olivier Messiaen y Pablo d'Ors: una relación en la escucha atenta de la plegaria». Diablo-Texto Digital 7: 122-141. https://doi.org/10.7203/ diablotexto.7.16779

Gadamer, Hans-Georg. 1991. La actualidad de lo bello. Barcelona: Paidós.

García Berrio, Antonio. 1989. Teoría de la literatura. Madrid: Cátedra.

Giddens, Anthony. 1997. Modernidad e identidad del yo. Barcelona: Península.

Gullón, Germán. 2004. Los mercaderes en el templo de la literatura. Madrid: Caballo de Troya.

Gullón, Ricardo. 1984. La novela lírica. Madrid: Cátedra.

Hutcheon, Linda. 1980. Narcissistic Narrative: The Metafictional Paradox. Ontario: Wilfrid Laurier University Press.

Ibáñez, Andrés. 2004. «Del correcaminos a los Teletubbies. Cambios en el paradigma narrativo». En Cuarentena. Nuevos narradores y críticos a principios del siglo XXI, coord. Antonio Orejudo, 125-150. Murcia: Universidad de Murcia.

Ives, Charles. 1982. Ensayos ante una sonata. México: Universidad Nacional Autónoma de México.

Laín Entralgo, Pedro. 1964. La aventura de leer. Madrid: Espasa-Calpe.

Lewis, C. S. 1982. Crítica literaria, un experimento. Barcelona: Bosch.

Mainer, José-Carlos. 1994. De postguerra (1951-1990). Barcelona: Crítica.

Navajas, Gonzalo. 2016. Teoría y práctica de la novela española posmoderna. Barcelona: Calambur.

Ors, Pablo d'. 2008. Lecciones de ilusión. Barcelona, Anagrama.

Ors, Pablo d'. 2013. Biografía del silencio. Madrid: Siruela.

Ortega y Gasset, José. 1987. Estafeta Romántica. Obras completas. III. Madrid: Alianza Editorial - Revista de Occidente.

Ortega y Gasset, José. 2000. Meditación de la técnica y otros ensayos sobre ciencia y filosofia. Madrid: Alianza Editorial - Revista de Occidente.

Pavel, Thomas. 2005. Representar la existencia. Barcelona: Crítica.

Platón. 1997. Diálogos III. Madrid: Gredos. 
Pozuelo Yvancos, José María. 2004. Ventanas de la ficción. Narrativa hispánica, siglos XX y XXI. Barcelona: Península.

Ricœur, Paul. 1987. Tiempo y narración. Configuración del tiempo en el relato de ficción. 2 Tomos. Madrid: Ediciones Cristiandad.

Rorty, Richard. 1996. Consecuencias del pragmatismo. Madrid: Tecnos.

Santiáñez, Nil. 2002. Modernidad, historia de la literatura y modernismos. Barcelona: Crítica.

Schlickers, Sabine. 2017. La narración perturbadora: un nuevo concepto narratológico transmedial. Madrid: Iberoamericana - Vervuet.

Sobejano, Gonzalo. 1988. «La novela ensimismada (1980-85)». España contemporánea: revista de literatura y cultura I, 1: 9-26.

Sobejano, Gonzalo. 2004. «Adelantados de la novela discursiva: Luis Goytisolo, Miguel Espinosa, Juan Benet». En La novela digresiva en España. XII Simposio Internacional sobre narrativa hispánica contemporánea, 9-16. Puerto de Santa María: Fundación Luis Goytisolo.

Steiner, George. 2000. Lenguaje y silencio. Barcelona: Gedisa.

Toro, Vera. 2017. «Soy simultáneo». El concepto poetológico de la autoficción en la narrativa hispánica. Madrid: Iberoamericana - Vervuet.

Torrecilla, Jesús. 2017. «Evasión y responsabilidad: el caso de Unamuno». En Ser y deber ser. Dilemas morales y conflictos éticos del siglo XIX vistos a través de la ficción, ed. Susanne Hartwig, 347-360. Madrid: Iberoamericana - Vervuet.

Trías, Eugenio. 1985. Los límites del mundo. Barcelona: Ariel.

Trías, Eugenio. 2014. El hilo de la verdad. Barcelona: Galaxia Gutenberg.

Unamuno, Miguel. 2005. Obras completas, VII. Madrid: Fundación José Antonio de Castro.

Valente, José Ángel. 2006. Obras completas II. Ensayos. Editado por Andrés Sánchez Robayna. Barcelona: Galaxia Guttember - Círculo de lectores.

Varo Varo, Alonso. 2018. «La mirada atenta en El estupor y la maravilla de Pablo d'Ors». Anales de la literatura española contemporánea 43: 161-182.

Varo Varo, Alonso. 2019. «La condición fronteriza en El amigo del desierto de Pablo d'Ors». Siglo XXI. Literatura y culturas españolas 17: 81-103. https://doi.org/10.24197/ sxxi.0.2019.81-103

Fecha de recepción: 27 de febrero de 2018.

Fecha de aceptación: 4 de septiembre de 2018. 